\title{
Mitigation of turbulence-induced scintillation and ASE noise using aperture averaging based on hybrid DPPM and OOK modulation of FSO systems
}

Ebrahim E. Elsayed ( $\nabla$ engebrahem16@gmail.com )

Electronics and Communications Engineering Department, Faculty of Engineering, Mansoura University, Mansoura 35516, El-Dakahilia Governorate, Egypt. https://orcid.org/0000-0002-7208-2194

\section{Research Article}

Keywords: Amplified spontaneous emission, Pointing error, Digital pulse position modulation, Free-space optical communication system, Modified Chernoff bound, Aperture-averaging

Posted Date: April 28th, 2021

DOI: https://doi.org/10.21203/rs.3.rs-467166/v1

License: (a) (i) This work is licensed under a Creative Commons Attribution 4.0 International License.

Read Full License 


\title{
Mitigation of turbulence-induced scintillation and ASE noise using aperture averaging based on hybrid DPPM and OOK modulation of FSO systems
}

\author{
Ebrahim E. Elsayed
}

\begin{abstract}
The performance evaluation of free-space optical (FSO) communication using a digital pulse position modulation (DPPM) is investigated in this paper. The impact of atmospheric turbulence, scintillation and amplified spontaneous emission (ASE) noise has been taken into account. To reduce the turbulence-induced scintillation and optical power penalty, the use aperture averaging (AA) has been proposed in this paper. To evaluate the bit-error rate (BER) performance in the presence the atmospheric turbulence and amplified spontaneous emission (ASE), the use of the moment generation function (MGF) techniques are explained with the modified Chernoff bound (MCB) that is more accurate and an appropriate from Chernoff bound (CB). Such a system, which could provide a power efficient, a low cost, excessive flexibility and reliable or considered a massive solution in the bandwidth provision for future access networks, and together for higher data rate. The BER, are given for an optically preamplified DPPM FSO communication system impaired by pointing error (PE) and atmospheric turbulence combined, in addition to the ASE noise arising from the optical amplification. The gamma-gamma (GG) distribution model is used to characterize the whole range of turbulence conditions. The results reveal the superiority of DPPM with improved receiver sensitivity (at a binary data rate 2.5 Gbps and at typical FSO BER of $10^{-9}$ ) of about $10 \mathrm{~dB}-11 \mathrm{~dB}$ for coding level (M) of 5 and optical link length (for turbulent interaction) of $2000 \mathrm{~m}$ more than an equivalent optically preamplified on-off keying non-return-to-zero (OOK-NRZ) approach, depending on the level of turbulence.
\end{abstract}

Keywords: Amplified spontaneous emission, Pointing error, Digital pulse position modulation, Free-space optical communication system, Modified Chernoff bound, Aperture-averaging

\section{Introduction}

In recent years, there has been a renewed interest in understanding and exploiting free-space optical (FSO) communication, mainly because of the large potential bandwidth available compared to radio frequency (RF) and its flexibility compared to optical fiber. FSO communication typically entails transmitting informationbearing near infrared light through the air between two or more transceivers. FSO has emerged as a commercially viable complementary technology to RF and millimeterwave systems [1-3]. An optical preamplifier configuration is used to increase power at the photodetector and thus effectively improve the receiver sensitivity. This benefit however comes with the drawback of having to manage the signal-to-noise ratio degradation due to the amplified spontaneous emission (ASE) noise arising from optical amplification, which in turn generates signal spontaneous and spontaneous-spontaneous beat noises. These are in addition to the usual electrical domain noises. Wavelength-

\footnotetext{
E-mail address: engebrahem16@gmail.com

Ebrahim E. Elsayed is with the department of Electronics and Communications Engineering, Faculty of Engineering, Mansoura University, Mansoura 35516, Egypt.
}

division-multiplexing (WDM) system has application in both optical fiber and FSO systems [4, 5, 6]. With WDM PON, fixed wavelengths are assigned to each optical network unit (ONU), thus more fully exploiting the hightransmission bandwidth available in the optical domain and avoiding the synchronization and threshold acquisition required in the burst mode upstream of time-division multiplexing/time division multiple access (TDM/TDMA) systems $[7,8]$. With the continuous increase in demand for bandwidth, WDM systems have been investigated and/or deployed for fiber, free space and wireless optical networks [9-11]. Multi-user access network scenarios may also be served by dense wavelength division multiplexing (DWDM), for example DWDM passive optical network (PON) is generally considered as a good solution to the bandwidth requirement for future access networks, with potential for higher data rate, improved data security and longer reach $[9,12]$. Compared to TDM/TDMA PONs, WDM PON systems offer other advantages to the users, such as low loss, greater security (due to dedicated wavelengths) and longer reach, and are increasingly being considered as the primary solution to the continuous rise in bandwidth demand in access networks $[13,14]$. In contrast to space-division multiplexing, DWDM supports network 
resource sharing, which generally reduces implementation cost. Furthermore, unlike code-division multiplexing and TDM where the system bit rate and chip rate may be higher than the end user's data rate, DWDM systems enable simultaneous transmission by all users at a full system bit rate only limited by the electronic processing speed [4]. Digital pulse-position modulation (DPPM) has successfully been applied in fiber, intersatellite, and deep space optical communication systems and is a strong contender for terrestrial FSO systems $[15,16]$. These advantages of the DPPM format however come at the expense of greater channel bandwidth requirements. Several studies on FSO systems show that digital pulse modulation schemes are more power efficient schemes compared to on-off-keying $(\mathrm{OOK})$ and are well suited for FSO communication systems where dispersion is negligible [17, 18, 19]. FSO systems are also affected by pointing error (PE) which arises due to inaccurate tracking systems or mechanical vibrations caused by natural phenomena (e.g. strong winds, thermal expansion and weak earthquakes) [20, 21]. Thus the existence of $\mathrm{PE}$ will further limit the optimal performance of the FSO system. Since the FSO system experiences significant performance impairment due to PE and turbulence it is advantageous to compensate for this and, of course, for coupling and atmospheric losses by the inclusion of optical amplification [17, 22]. Thus the combined effects of atmospherically-induced scintillation and $\mathrm{PE}$ due to building sway on an optically preamplified FSO system are the main focus here. This brings together the analyses of PE found in [3, 4] with the BER evaluation approach used by the present authors in previous work [17, 22]. Yamamoto [23] derived expressions for the mean and variance of an optically preamplified signal, in order to facilitate a Gaussian approximation (GA). However this is not a full description of the signal plus ASE noise, which is not really Gaussian distributed but instead is related to chisquare (ASE only) and non-central chi-square (signal plus ASE) distributions. Several diversity techniques have been proposed in the literature for mitigating turbulence-induced scintillation in FSO communication systems. Some of the common methods include time diversity, spatial diversity using multiple transmitters and/or receivers and aperture averaging (AA) [1, 3]. Due to the simplicity and effectiveness of the aperture averaging technique, its impact in the WT, MT and ST regimes will be investigated in this study. Personick [24] and, later, Ribeiro et al. [25] derived alternative formulations based on a moment generating function (MGF), which gives a full statistical description of a system employing an optically preamplified direct detection receiver. Bit error rate (BER) in [23-25] for OOK systems is then evaluated using MGF based techniques such as Chernoff bound (CB) and modified Chernoff bound (MCB). The lognormal (LN), gamma- gamma (GG), K (KD) and negative exponential (NE) distributions are employed in this work and the results obtained are compared with the customary GA approach. The reminder paper is organized as follows: Section 2 describes the optically preamplified receiver. Section 3 presents the DPPM crosstalk modeling. Section 4 evaluates of the atmospheric turbulence models. Section 5 evaluates the moment generation function analysis. Section 6 introduces the bit error rate (BER) analysis. Section 7 shows the results and discussions. Section 8 concludes this paper.

\section{Optically preamplified receiver}

The performance of a standard a positive-intrinsic-negative (PIN) direct detection receiver configuration for an FSO communication system can be improved significantly by using an optical preamplifier after the receiver collecting lens (RCL), as shown in Fig. 1. An optical amplifier of gain $\mathrm{G}$ and noise figure $\mathrm{NF}$ is placed before the photodiode. The incoming optical signal is coupled by means of a collimator into a short fiber through which it is fed into the optical amplifier. An optical bandpass filter (OBPF) of optical bandwidth $\mathrm{B}_{\mathrm{o}}$ is placed between the optical amplifier and the photodiode. At the receiver, the receiver collecting lens (RCL) is assumed to be perfectly aligned with the transmitter lens in a pointing and tracking scheme. It collects the incident laser beam which is coupled to a fiber using a collimator (following [26]) and then optically amplified. The process of optical preamplification produces ASE noise whose field is statistically described as Gaussian. The optical amplifier has a gain, G. In addition to the amplified optical signal, amplified spontaneous emission (ASE) noise is generated, with power spectral density $\mathrm{N}_{\mathrm{o}}=0.5(\mathrm{NF} \times \mathrm{G}-1) \mathrm{E}$ (in single polarization), where $\mathrm{E}$ is the photon energy and NF is the noise figure. In the electrical domain, the ASE beats with the signal and itself to form the signal-spontaneous and spontaneous-spontaneous beat noises, respectively. The optical bandpass filter with bandwidth $\mathrm{B}_{\mathrm{o}}$ precedes the pin photodiode (of quantum efficiency $\eta$ ) and helps to reduce the ASE power incident on it. The decision circuitry is modelled by an integrate-and-dump filter over $t_{s}$ whose result obtained per frame are compared in order to obtain the slot (and hence word) with the highest value. $m_{t}$ is number of polarization modes for ASE noise and $\mathrm{R}=$ $\eta / \mathrm{E}$.

\section{DPPM crosstalk modelling}

Digital pulse position modulation (DPPM) is one of the schemes that use the time-varying properties of a pulse train, with each data binary-word submitted by the distinct position of a signal pulse in a time frame. In the DPPM scheme illustrated in Fig. 2, a frame of duration equal to $\mathrm{MT}_{\mathrm{b}}$ is divided into $n=2^{M}$ equal time slots of length $\mathrm{t}_{\mathrm{s}}=\mathrm{MT}_{\mathrm{b}} / \mathrm{n}$, where $\mathrm{M}$ is the coding level and is equal to the number of data bits transmitted per DPPM frame. Also, $T_{b}=1 / R_{b}$ is the equivalent OOK-NRZ bit period and $R_{b}$ is the raw bit rate. An input word is then represented by placing an optical pulse in one of the DPPM time slots in the frame. In this analysis, the incident DPPM signal is 


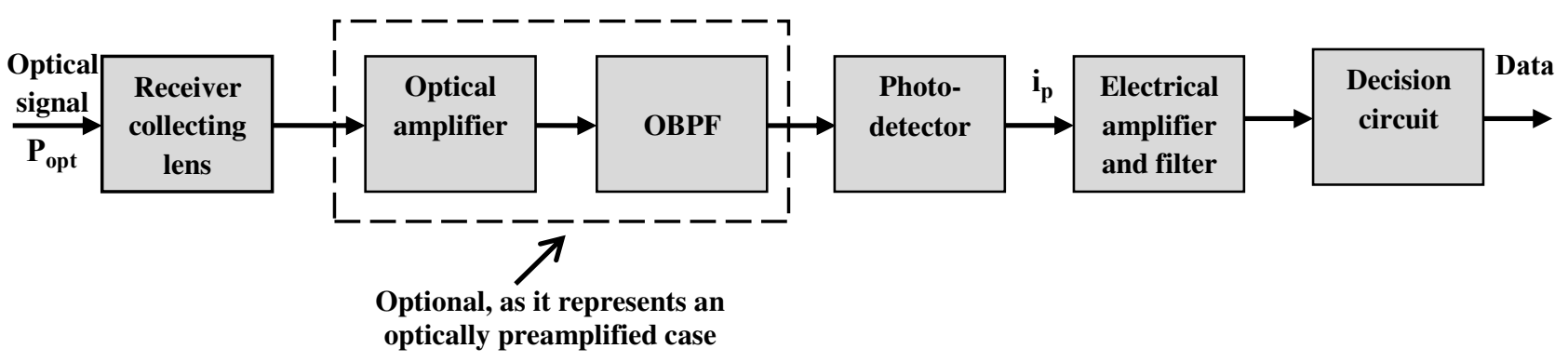

Fig. 1 Block diagram of optically FSO receiver
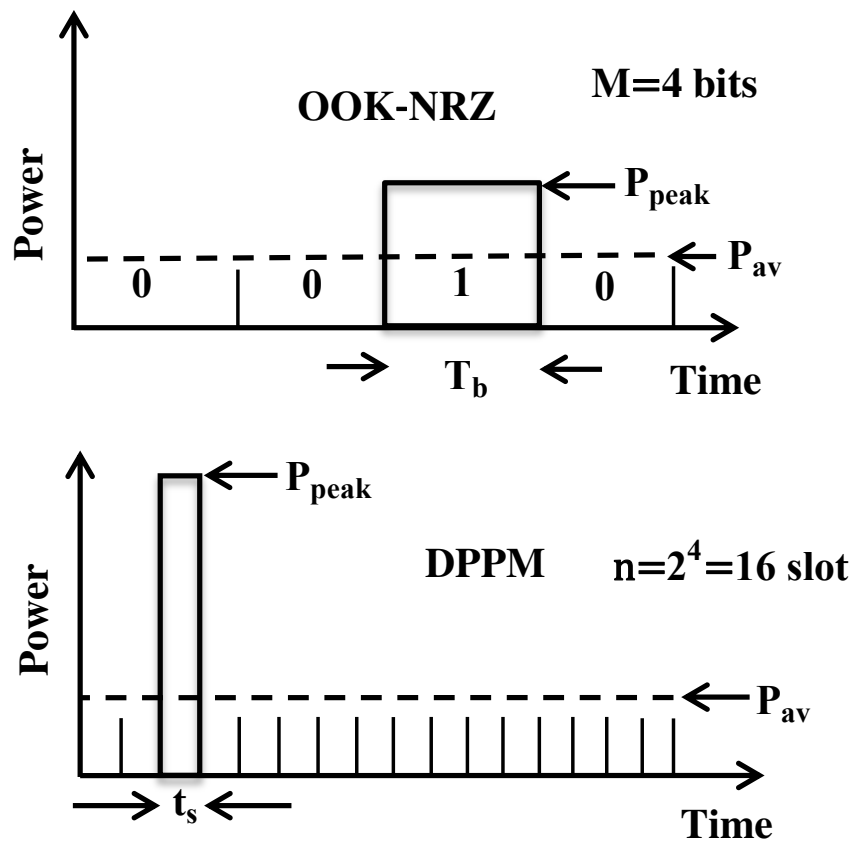

Fig. 2 Illustration of OOK-NRZ and DPPM frame for $M=4(n=$ $2^{4}=16$ slots)

detected by integrating over each DPPM slot and comparing the results throughout the frame to obtain the largest result $[15,27]$.This advantage is at a yield of increasing bandwidth improvement which is better popular at high coding level or bit resolution. In extension, DPPM requests for a splitting synchronization unit which continues to receiver complication and for a dispersive channel such as an optical fiber, guard bands are needed to break up each signal frame from another. Each frame subsists of a single pulse occupying one DPPM slot and the pulse position in the frame corresponds to the value of the $\mathrm{M}$ bit word. Each frame consists of a single pulse occupying one DPPM slot and the pulse position in the frame corresponds to the value of the $M$ bit word. Fig. 2 illustrates the OOK-NRZ and equivalent 16-DPPM signal. The achievement of timing synchronization has been investigated for FSO systems [28, 29]. Further, the DPPM receiver is controlled by slot synchronization and frame synchronization circuits, as shown in Fig. 1.

\section{Atmospheric turbulence models}

In clear air conditions, optical beam propagation through the atmosphere is particularly affected by turbulenceinduced scintillation which significantly reduces the performance of the link [1, 30, 31]. The major consequence of scintillation is fluctuations in the irradiance at the receiver which results in high BERs [1]. FSO links are commonly classified into various levels of turbulence using the Rytov variance $\sigma_{\mathrm{R}}^{2}$, which is given by $[1,3,30$, $32,33]$

$\sigma_{\mathrm{R}}^{2}=1.23 \mathrm{C}_{\mathrm{n}}^{2} \mathrm{k}^{7 / 6} l_{\mathrm{fso}}^{11 / 6}$

where $C_{n}^{2}$ is the refractive index structure constant takes values typically within (ranging from $\approx 10^{-17} \mathrm{~m}^{-2 / 3}$ to $\left.\approx 10^{-13} \mathrm{~m}^{-2 / 3}\right)[3,30], l_{\text {fso }}$ is the FSO link length, $k=2 \pi / \lambda$ is the wave number, and $\lambda$ is the wavelength 
[29, 30, 33]. The Rytov variance distinguishes the various link turbulence regimes $\sigma_{\mathrm{R}}^{2}$ if the resulting $\sigma_{\mathrm{R}}^{2}<1$, we have weak turbulence (WT); if $\sigma_{\mathrm{R}}^{2} \approx 1$, we have moderate turbulence (MT) and if $\sigma_{\mathrm{R}}^{2}>1$; we have strong turbulence (ST), and if saturated turbulence $\sigma_{R}^{2} \rightarrow \infty$ are given as from $[1,3,30]$. The effects of turbulence are characterized using the gamma-gamma (GG) probability density function (pdf), which is given as [1, 3, 30, 32, 33]

$p_{\mathrm{GG}}\left(h_{\mathrm{turb}}\right)=\frac{2(\alpha \beta)^{(\alpha+\beta) / 2}}{\Gamma(\alpha) \Gamma(\beta)} h_{Z}^{((\alpha+\beta) / 2)-1} K_{\alpha-\beta}\left(2 \sqrt{\alpha \beta h_{\mathrm{turb}}}\right)$;

$h_{\text {turb }}>0$

where $h_{\text {turb }}$ is the attenuation because of atmospheric turbulence, $\alpha$ and $\beta$ are the effective number of large-scale and small-scale eddies of the scattering process, respectively, $K_{n}(\cdot)$ is the modified Bessel function of second kind, order $n$ and $\Gamma(\cdot)$ is the gamma function. The signal and interferer travel over physically distinct paths in the upstream and thus have uncorrelated turbulence; hence, their GG pdfs are each treated independently. The parameter $\alpha$ and $\beta$ for plane-wave propagation for arbitrary aperture size are given as $[1,3,33]$

$\alpha=\left\{\exp \left[\frac{0.49 \sigma_{\mathrm{R}}^{2}}{\left(1+0.65 \mathrm{~d}^{2}+1.11 \sigma_{\mathrm{R}}^{12 / 5}\right)^{7 / 6}}\right]-1\right\}^{-1}$,

$\beta=\left\{\exp \left[\frac{0.51 \sigma_{\mathrm{R}}^{2}\left(1+0.69 \sigma_{\mathrm{R}}^{12 / 5}\right)^{-5 / 6}}{1+0.9 \mathrm{~d}^{2}+0.62 \mathrm{~d}^{2} \sigma_{\mathrm{R}}^{12 / 5}}\right]-1\right\}^{-1}$,

$\mathrm{d}=\sqrt{k \mathrm{D}_{\mathrm{RX}}^{2} / 4 l_{\mathrm{fso}}}$

where $\mathrm{d}$ is the normalized receiver collecting lenses normalized (RCLs) [30, 33], Aperture averaging (AA) is a commonly used method for mitigating turbulence-induced scintillation [1, 3, 33, 34, 35]. This method essentially entails increasing the RCL area such that it is larger than the fluctuating irradiance correlation width $\rho_{o}=$ $\left(1.46 \mathrm{C}_{\mathrm{n}}^{2} \mathrm{k}^{2} l_{\mathrm{fso}}\right)^{-3 / 5}$ [1], resulting in averaging of the irradiance fluctuations over the RCL area such that a significant reduction in scintillation is achieved compared to that observed for a point receiver [1, 3, 33-35]. The decrease in irradiance fluctuation is typically measured using the AA factor $A=\sigma_{1}^{2}\left(\mathrm{D}_{\mathrm{RX}}\right) / \sigma_{1}^{2}(0)$ [33], where $\sigma_{\mathrm{l}}^{2}\left(\mathrm{D}_{\mathrm{RX}}\right)$ is the scintillation index for RCL diameter $D_{R X}\left(D_{R X}=0\right.$ for a point receiver $)$ and is given as [33]

\section{Moment generation function analysis}

For a given irradiance I the optical power at the optical amplifier input during OOK NRZ bit of data $\mathrm{j}\{0,1\}$ is expressed mathematically as

$P_{\mathrm{j}}(\mathrm{I})=a_{j} I A$

where $a_{1}=2 r /(r+1), a_{0}=2 /(r+1), A$ is the area of the receiver aperture and $\mathrm{r}$ is the extinction ratio (typically 10 ). Clearly $I$ is the mean irradiance for the bit stream at a particular time. The MGF (conditional on $I$ ) can then be obtained from, for example [25], under the assumption of an integrating response over bit period $\mathrm{T}$ (which has a noise equivalent bandwidth $\mathrm{B}_{\mathrm{e}}=1 / 2 \mathrm{~T}$ ) [22]

$M_{Y_{j}}(s / I)=\frac{\exp \left[\mathrm{R}^{\prime} \operatorname{GsqP}_{\mathrm{j}}(\mathrm{I}) /\left(1-\left(\mathrm{R}^{\prime} \mathrm{N}_{0} \mathrm{sq} / \mathrm{T}\right)\right)\right]}{\left[1-\left(\mathrm{R}^{\prime} \mathrm{N}_{0} \mathrm{sq} / \mathrm{T}\right)\right]^{\mathrm{L}}}$

where $q$ is the electron charge, $\mathrm{s}$ is the standard parameter in the transform domain for the MGF, $\mathrm{L}=\mathrm{B}_{0} \mathrm{~m}_{\mathrm{t}} \mathrm{T}$ is the product of spatial and temporal modes, $B_{0}$ is the OBPF bandwidth in $\mathrm{Hz}, \mathrm{m}_{\mathrm{t}}=2$ is number of polarization modes, $\mathrm{N}_{\mathrm{O}}=\mathrm{n}_{\mathrm{sp}}(\mathrm{G}-1) h f$ is the ASE power spectral density (PSD) in $\mathrm{W} / \mathrm{Hz}$ (in single polarization), $n_{s p}$ is the spontaneous emission factor, $\mathrm{R}^{\prime}=\eta / h f, \mathrm{G}$ is the optical amplifier gain, $h$ is the Planck's constant and $f$ is the optical frequency in $\mathrm{Hz}$. On introducing the Gaussian receiver thermal noise, a new overall conditional MGF for the signal at the decision device is obtained [25]

$M_{Z_{j}}(s / I)=M_{t h}(s) M_{Y_{j}}(s / I)$

where $M_{t h}(s) M_{Y_{j}}=\exp \left(\sigma_{\mathrm{th}}^{2} \mathrm{~s}^{2} / 2\right)$ is the thermal noise MGF and $\sigma_{\mathrm{th}}^{2}$ is the thermal noise variance at the decision circuit. The conditioning of the MGF on $I$ will be removed in the BER calculation in the next section.

\section{Bit error rate analysis}

In this section, the application of MGF methods, specifically the $\mathrm{CB}$ and MCB for the BER evaluation is presented for weak-to-strong turbulence regimes, using the LN, GG, KD and NE atmospheric turbulence models. The BER for a given irradiance $I$ is given as [17]

$\operatorname{BER}(\mathrm{I})=\frac{1}{2}[P(1 \mid 0, I)+P(0 \mid 1, I)]$

where $\mathrm{P}(1 \mid 0, \mathrm{I})$ represents the probability of receiving a 1 given that 0 was transmitted and $\mathrm{P}(0 \mid 1, \mathrm{I})$ represents the probability of receiving a 0 given that 1 was transmitted. On applying the CB separately to each conditional probability, (9) and (10) are obtained [17] 
$\mathrm{P}(1 \mid 0, I)=\mathrm{P}\left(i_{o}(I)>i_{D}(I)\right)$
$\leq \exp \left(-s_{0} i_{D}(I)\right) M_{Z_{0}}\left(\mathrm{~s}_{0}, I\right), \quad \mathrm{s}_{0}>0$

$\mathrm{P}(0 \mid 1, I)=\mathrm{P}\left(i_{1}(I)>i_{D}(I)\right)$

$\leq \exp \left(-s_{1} i_{D}(I)\right) M_{Z_{1}}\left(-\mathrm{s}_{1}, I\right), \quad \mathrm{s}_{0}>0$

where $i_{D}(I)$ is the decision threshold. The CB therefore gives the upper bound on the BER as

$$
\begin{aligned}
& \mathrm{BER}_{\mathrm{CB}}(I) \\
& =\frac{1}{2}\left[\operatorname { e x p } \left(-\left(-s i_{D}(I)\right) M_{Z_{0}}(\mathrm{~s}, I)\right.\right. \\
& \left.\left.+\exp \left(\operatorname{si}_{D}(I)\right) M_{Z_{1}}(-\mathrm{s}, I)\right)\right] \mathrm{s}=\mathrm{s}_{0}=\mathrm{s}_{1}>0
\end{aligned}
$$

where $M_{Z_{0}}(\mathrm{~s}, I)$ and $M_{Z_{1}}(\mathrm{~s}, I)$ are given by (8). The setting of $\mathrm{s}=\mathrm{s}_{0}=\mathrm{s}_{1}$ is a computational convenience that incurs a very small accuracy penalty (as $s_{0}$ and $s_{1}$ can of course be optimized separately) [25]. By replacing the optical link length $\mathrm{z}$ with $l_{\text {fso }}$. The beam width of a Gaussian laser beam $w_{z}$ due to diffraction and turbulence effects grows with the optical link length $z=l_{\text {fso }}$, and it is given as [1]

$w_{z}=w_{0}\left(\sqrt{1+\left(\mathrm{z} / \mathrm{z}_{\mathrm{L}}\right)^{2}}\right) \times$

$\left(\sqrt{1+1.33 \sigma_{R}^{2}\left(2 z / k w_{0} \sqrt{1+\left(z / z_{L}\right)^{2}}\right)^{5 / 6}}\right)$

where $w_{0}$ is the minimum value of $w_{z}$ at a point $(\mathrm{z}=0)$ along the beam axis and $z_{L}=\pi w_{0}^{2} / 2$ is called the Rayleigh range. The Gaussian beam at the receiver is approximated as plane wave for aspects such as the turbulence modelling and the beam characterization of this analysis, though the pointing error analysis relies on its Gaussian nature. The pdf for attenuation due to PE and geometric spread (GS) is given as [20, 21]

$p_{P E}\left(h_{p}\right)=\frac{\gamma^{2}}{A_{0}^{\gamma^{2}}} h_{p}^{\gamma^{2}-1} ; 0 \leq h_{p} \leq A_{0}$,

where $h_{p}$ is attenuation due to GS and PE, $\gamma=w_{\mathrm{z}_{\mathrm{eq}}} / 2 \sigma_{\mathrm{PE}}$, jitter-induced PE standard deviation at the receiver is $\sigma_{\mathrm{PE}}$, $w_{z_{e q}}^{2}=w_{z}^{2} \sqrt{\pi} \operatorname{erf}(v) / 2 v \exp \left(-v^{2}\right)$ is the (square of the) equivalent beam width, $A_{0}=[\operatorname{erf}(v)]^{2}$ is the fraction of the collected power at receiver radial displacement of zero, and $\quad v=\left(\sqrt{\pi} \mathrm{r}_{\mathrm{RX}}\right) /\left(\sqrt{2} w_{\mathrm{z}}\right)$. The combined pdf for attenuation due to turbulence, PE and GS can then be expressed as [20,21]

$$
p\left(h_{t o t}\right)=\int p_{P E}\left(h_{\mathrm{tot}} \mid h_{a}\right) p_{\mathrm{GG}}\left(h_{a}\right) d h_{a}
$$

where $h_{\text {tot }}=h_{a} h_{p}$ and $p_{P E}$ is the probability distribution for PE conditioned on $h_{a}$, such that [36]

$$
\begin{aligned}
\int p_{P E}\left(h_{\mathrm{tot}} \mid h_{a}\right) & =\frac{1}{h_{a}} p_{P E}\left(\frac{h_{\mathrm{tot}}}{h_{a}}\right)=\frac{\gamma^{2}}{A_{0}^{\gamma^{2}}}\left(\frac{h_{\mathrm{tot}}}{h_{a}}\right)^{\gamma^{2}-1} ; 0 \\
& \leq h_{\mathrm{tot}} \leq A_{0} .
\end{aligned}
$$

On substituting (2) and (16) into (15), the combined pdf can be re-written as [36]

$$
\begin{aligned}
& p_{\mathrm{GG}}\left(h_{\mathrm{tot}}\right)=\frac{2 \gamma^{2}(\alpha \beta)^{(\alpha+\beta) / 2}}{A_{0}^{\gamma^{2}} \Gamma(\alpha) \Gamma(\beta)} h_{\mathrm{tot}}^{\gamma^{2}-1} \\
& \times \int_{h_{\mathrm{tot}} / A_{0}}^{\infty} h_{a}^{\frac{(\alpha+\beta)}{2}-1-\gamma^{2}} K_{\alpha-\beta}\left(2 \sqrt{\alpha \beta h_{a}}\right) \mathrm{d} h_{a}
\end{aligned}
$$

The DPPM BER is given by [3, 8, 15], here noting the dependence on $h_{t u r b}$ relevant to the current discussion

$\operatorname{BER}\left(h_{\text {turb }}, P\right)=\frac{n P_{w e}\left(h_{\text {turb }}, P\right)}{2(n-1)}$

where $P_{\mathrm{we}}\left(h_{\text {turb }}, P\right)$ is the symbol error probability. Following the treatment of [15], given that each transmitted word has equal probability, the probability of successful reception of a word $P_{\mathrm{ws}}\left(h_{\text {turb }}, P\right)=1-$ $P_{\text {we }}\left(h_{\text {turb }}, P\right)$ is bounded by exploiting the fact that for a particular frame, the events $\left\{X_{\mathrm{tr}}>X_{1}\right\}, \ldots,\left\{X_{\mathrm{tr}}>\right.$ $\left.X_{\mathrm{j}}\right\}, \ldots,\left\{X_{\mathrm{tr}}>X_{\mathrm{n}}\right\}$ (excluding, the case of $\mathrm{j}=\mathrm{tr}$ ) are each no less likely to occur given that any combination of the others have also occur and write that [17]

$$
\begin{aligned}
P_{\mathrm{ws}}\left(h_{\text {turb }}, P\right) \geq & \prod_{\substack{j=1 \\
j \neq t r}}^{n} P\left(X_{\mathrm{tr}}>X_{\mathrm{j}} \mid h_{\text {turb }}, P\right) \\
& =\left(P\left(X_{\mathrm{tr}}>X_{\mathrm{f}} \mid h_{\text {turb }}, P\right)\right)^{n-1}
\end{aligned}
$$

Then $P_{w e}\left(h_{t u r b}, P\right)$ can be expressed as [15]

$$
P_{\mathrm{we}}\left(h_{\text {turb }}, P\right) \leq 1-\left(P\left(X_{\mathrm{f}}>X_{\mathrm{tr}} \mid h_{\text {turb }}, P\right)\right)^{n-1}
$$

Under the assumption that the random variables $X_{\mathrm{tr}}$ and $X_{\mathrm{f}}$ are Gaussian, the GA expression for $P_{w e, G A}\left(h_{t u r b}, P\right)$ is given by using (20) [15] 


$$
\begin{aligned}
& P_{w e, G A}\left(h_{\text {turb }}, P\right) \\
& \leq 1-\left(1-0.5 \operatorname{erfc}\left(\frac{\mu_{X_{t r}}\left(h_{t u r b}, P\right)-\mu_{X_{f}}}{\sqrt{2\left(\sigma_{X_{t r}}^{2}\left(h_{t u r b}, P\right)+\sigma_{X_{f}}^{2}\right)}}\right)\right)^{n-1}
\end{aligned}
$$

The application of an upper bound upon $P_{\mathrm{we}}\left(h_{t u r b}, P\right)$ using $\mathrm{CB}$ technique will also yield upper bound upon $P\left(X_{\mathrm{f}}>X_{\mathrm{tr}}\right)$; hence for $s>0$, the CB is given as [15]

$$
\begin{aligned}
& P\left(X_{\mathrm{f}}>X_{\mathrm{tr}} \mid h_{t u r b}, P\right) \\
& \leq M_{X_{\mathrm{f}}}\left(\mathrm{s} \mid h_{t u r b}, P\right) M_{X_{\mathrm{tr}}}\left(-s \mid h_{t u r b}, P\right) \quad(\mathrm{s}>0)
\end{aligned}
$$

The tightest $\mathrm{CB}$ can be obtained by finding the optimum value of $s$ (i.e. $\mathrm{s}_{\mathrm{opt}}$ ) [15]

$$
\begin{aligned}
& P_{\mathrm{we}, \mathrm{CB}}\left(h_{t u r b}, P\right) \\
& \leq 1-\left(1-M_{X_{\mathrm{tr}}}\left(-\mathrm{s}_{\mathrm{opt}} \mid h_{t u r b}, P\right) M_{X_{\mathrm{f}}}\left(\mathrm{s}_{\mathrm{opt}} \mid h_{t u r b}, P\right)\right)^{n-1}
\end{aligned}
$$

The general case for the MCB is $P(X>\varphi) \leq$ $\exp (-s \varphi) M_{X}(s) / s \sigma_{t h} \sqrt{2 \pi}$ where $\varphi$ is fixed and $\mathrm{X}$ includes a Gaussian component of variance $\sigma_{\mathrm{th}}^{2}$. In comparing $X_{\mathrm{f}}$ and $X_{\text {tr }}$ whose Gaussian components each have variance $\sigma_{\mathrm{th}}^{2}$, the effective variance of the Gaussian contribution becomes $\sigma_{\text {th }}^{2}=2 \sigma_{\text {th }}^{2}$ so yielding [17]

$P\left(X_{\mathrm{f}}>X_{\mathrm{tr}} \mid h_{t u r b}, P\right) \leq \frac{M_{X_{\mathrm{f}}}\left(\mathrm{s} \mid h_{t u r b}, P\right) M_{X_{\mathrm{tr}}}\left(-s \mid h_{t u r b}, P\right)}{s \sigma_{t h}^{\prime} \sqrt{2 \pi}}$

This MCB expression (24) is then used, with (20), to obtain

$$
\begin{aligned}
& P_{\mathrm{we}, \mathrm{MCB}}\left(h_{t u r b}, P\right) \\
& \leq 1-\left(1-\left(\frac{M_{X_{\mathrm{tr}}}\left(-\mathrm{s}_{\mathrm{opt}} \mid h_{t u r b}, P\right) M_{X_{\mathrm{f}}}\left(\mathrm{s}_{\mathrm{opt}} \mid h_{t u r b}, P\right)}{2 s \sigma_{t h}^{\prime} \sqrt{2 \pi}}\right)\right)
\end{aligned}
$$

The overall DPPM BER is given as

$$
\operatorname{BER}_{\mathrm{Z}, \mathrm{GG}}(P)=\int_{0}^{\infty} \operatorname{BER}_{\mathrm{Z}}\left(h_{t u r b}, P\right) p_{\mathrm{GG}}\left(h_{t u r b}\right) \mathrm{d} h_{t u r b}
$$

where $\operatorname{BER}_{\mathrm{Z}}\left(h_{\text {tur }}, P\right)$ represents the BERs obtainable from (18) using the $P_{\text {we }}\left(h_{\text {turb }}, P\right)$ bounds of (21), (23) and (25) (Z
$=\mathrm{GA}, \mathrm{CB}$ and $\mathrm{MCB}$ ) while $p_{\mathrm{GG}}\left(h_{\text {turb }}\right)$ represents the GG atmospheric turbulence model given in (2). Hence, to perform the integration in (26) numerically, the $\mathrm{s}_{\mathrm{opt}}$ must be found for each step in the integration.

\section{Results and discussions}

The parameters used in this model are presented in Table 1 and 2 . Three different atmospheric conditions characterized by the refractive-index structure parameter $C_{n}^{2}$ were taken into consideration. The WT, MT and ST regimes are considered, for which we set $\mathrm{C}_{\mathrm{n}}^{2}=4.74 \times 10^{-15} \mathrm{~m}^{-2 / 3}, \mathrm{C}_{\mathrm{n}}^{2}=$ $3.8 \times 10^{-14} \mathrm{~m}^{-2 / 3}$ and $\mathrm{C}_{\mathrm{n}}^{2}=8.3 \times 10^{-14} \mathrm{~m}^{-2 / 3}$, respectively, and $l_{f s o}=1500$ and $2000 \mathrm{~m}$. Using (1), he calculated Rytov variances are $\sigma_{\mathrm{R}}^{2}=0.2(\mathrm{WT}), \sigma_{\mathrm{R}}^{2}=1.60(\mathrm{MT}), \sigma_{\mathrm{R}}^{2}=3.51(\mathrm{ST})$, and $\sigma_{R}^{2}=0.310(\mathrm{WT}), \sigma_{\mathrm{R}}^{2}=2.701(\mathrm{MT}), \sigma_{\mathrm{R}}^{2}=5.89(\mathrm{ST})$, for $l_{f s o}=1500$ and $2000 \mathrm{~m}$, respectively. The DPPM thermal noise variance is back calculated using a bandwidth expansion factor such that $\sigma_{\mathrm{th}-\mathrm{DPPM}}^{2}=\mathrm{B}_{\mathrm{exp}} \sigma_{\mathrm{th}-\mathrm{OOK}}^{2}$ where $\mathrm{B}_{\text {exp }}=2^{\mathrm{M}} / M[37]$ is the DPPM bandwidth expansion factor and $\sigma_{\text {th-OOK }}^{2}=7 \times 10^{-7} \mathrm{~A}$ is obtained from a model of a positive-intrinsic-negative (PIN)-field effect transistor (FET) receiver with $\mathrm{R}_{\mathrm{b}}=2.5 \mathrm{Gbps}$ at BER of $10^{-12}$ assuming a sensitivity of $-23 \mathrm{dBm}$ [38]. The demux (or OBPF) channel bandwidth is $80 \mathrm{GHz}$ with $100 \mathrm{GHz}$ adjacent channel spacing, this is about the same with those seen in $[39,40]$ and will easily accommodate the slot rate of $45.7 \mathrm{GHz}$ for maximum DPPM coding level of $\mathrm{M}=7$ considered [17]. Typical values for adjacent channel rejection ratio ranges from $-20 \mathrm{~dB}$ to $-30 \mathrm{~dB}$ [39-41]. In the MT case (Fig 3, an improvement in required optical power of approximately $14 \mathrm{~dB}$ (MT with GS case) and 22 $\mathrm{dB}\left(\sigma_{\mathrm{PE}} / \mathrm{r}_{\mathrm{RX}}=3\right)$ and $2 \mathrm{~dB}\left(\sigma_{\mathrm{PE}} / \mathrm{r}_{\mathrm{RX}}=5\right)$ for both modulation formats, at target BER of $10^{-9}$ for $\mathrm{D}_{\mathrm{RX}} 25 \mathrm{~mm}$ [36]. In the ST case (Fig. 4), an improvement in required optical power of approximately $14 \mathrm{~dB}$ (ST with GS case) and $22 \mathrm{~dB}$ (for $\sigma_{\mathrm{PE}} / \mathrm{r}_{\mathrm{RX}}=3$ ) and $2 \mathrm{~dB}$ (for $\sigma_{\mathrm{PE}} / \mathrm{r}_{\mathrm{RX}}=3$ ) (ST, PE and GS case) for both modulation formats, at target BER of $10^{-9}$ was seen for increasing $D_{R X}$ from 25 to $50 \mathrm{~mm}$. In Figs. 3, 4, the BER for both modulation formats (MT and ST with GS cases) at $\sigma_{\mathrm{PE}} / \mathrm{r}_{\mathrm{RX}}=0.1$ are all seen to be similar to the turbulence plus GS only cases. This happens since the PE contribution would be relatively small at this value and the use of AA helps to reduce the $\mathrm{PE}$ and turbulence effect. Thus the $\sigma_{\mathrm{PE}} / \mathrm{r}_{\mathrm{RX}}=0.1$ can be approximated as a turbulence only case. Further, note that the effects of $\sigma_{\mathrm{PE}} / \mathrm{r}_{\mathrm{RX}}=0.1$ can be more significant for the point receiver case shown (without optical amplification) in [21]. It can be deduced from the plots (Figs 3 and 4) that the DPPM technique is capable of providing better performance when compared to the OOK-NRZ technique. From the results shown, at $\mathrm{M}=5, \sigma_{\mathrm{PE}} / \mathrm{r}_{\mathrm{RX}}=3$ and $\mathrm{D}_{\mathrm{RX}}=$ $50 \mathrm{~mm}$, a required optical power advantage of about $9 \mathrm{~dB}$ (NT with GS), $8 \mathrm{~dB}$ (WT, PE and GS), $7 \mathrm{~dB}$ (MT, PE and GS), and $7 \mathrm{~dB}$ (WT, PE and GS). The similarity between the MT and ST BERs (seen in Figs. 3 and 4) can be traced to the leveling effect $[1,33]$ which happens when the 
Table 1 Parameters used in calculations for Refs. [17, 42] and [Present Work]

\begin{tabular}{cllll}
\hline Parameters & Description & Ref. [17] & Ref. [42] & Values [Present Work] \\
\hline$R_{\mathrm{b}}$ & Binary data rate & $2.5 \mathrm{Gbps}$ & $2.5 \mathrm{Gbps}$ & $2.5 \mathrm{Gbps}$ \\
$\mathrm{B}_{\mathrm{opt}}$ & Demux channel optical noise bandwidth & $80 \mathrm{GHz}$ & $76 \mathrm{GHz}$ & $80 \mathrm{GHz}$ \\
$\lambda_{\mathrm{sig}}$ & Signal wavelength & $1550 \mathrm{~nm}$ & $1550 \mathrm{~nm}$ & $1550 \mathrm{~nm}$ \\
$\eta$ & Receiver quantum efficiency & 0.75 & 0.9 & 1 \\
$\mathrm{G}$ & Optical preamplifier gain & $30.6 \mathrm{~dB}$ or $8.8 \mathrm{~dB}$ & $27 \mathrm{~dB}$ or $8 \mathrm{~dB}$ & $30 \mathrm{~dB}$ \\
$\mathrm{NF}$ & Optical preamplifier noise figure & $4.77 \mathrm{~dB}$ & $4.77 \mathrm{~dB}$ & $4.77 \mathrm{~dB}$ \\
$\boldsymbol{l}_{\mathrm{fso}}$ & Optical link length & $1000 \mathrm{~m}$ and $1500 \mathrm{~m}$ & $1000 \mathrm{~m}$ and $1500 \mathrm{~m}$ & $1500 \mathrm{~m}$ and $2000 \mathrm{~m}$ \\
$\mathrm{~m}_{\mathrm{t}}$ & Polarization states of ASE noise & 2 & 2 & 2 \\
\hline
\end{tabular}

receiver diameter (e.g. $25 \mathrm{~mm}$ ) used falls between the values for the plane wave spatial coherence radius $\rho_{0}$ (which is calculated as $8.2 \mathrm{~mm}$ for $l_{f s o}=1500 \mathrm{~m}$ and $\mathrm{C}_{\mathrm{n}}^{2}=$ $3.8 \times 10^{-14} \mathrm{~m}^{-2 / 3}$ and the scattering disk $z / k \rho_{0}$ (which is calculated as $45 \mathrm{~mm}$ for $l_{f s o}==1500 \mathrm{~m}$ and $\mathrm{C}_{\mathrm{n}}^{2}=3.8 \times$ $10^{-14} \mathrm{~m}^{-2 / 3}$. When the diameter lies outside this range, but close to it, (e.g. $50 \mathrm{~mm}$ ) the effect is still present to some extent [36].

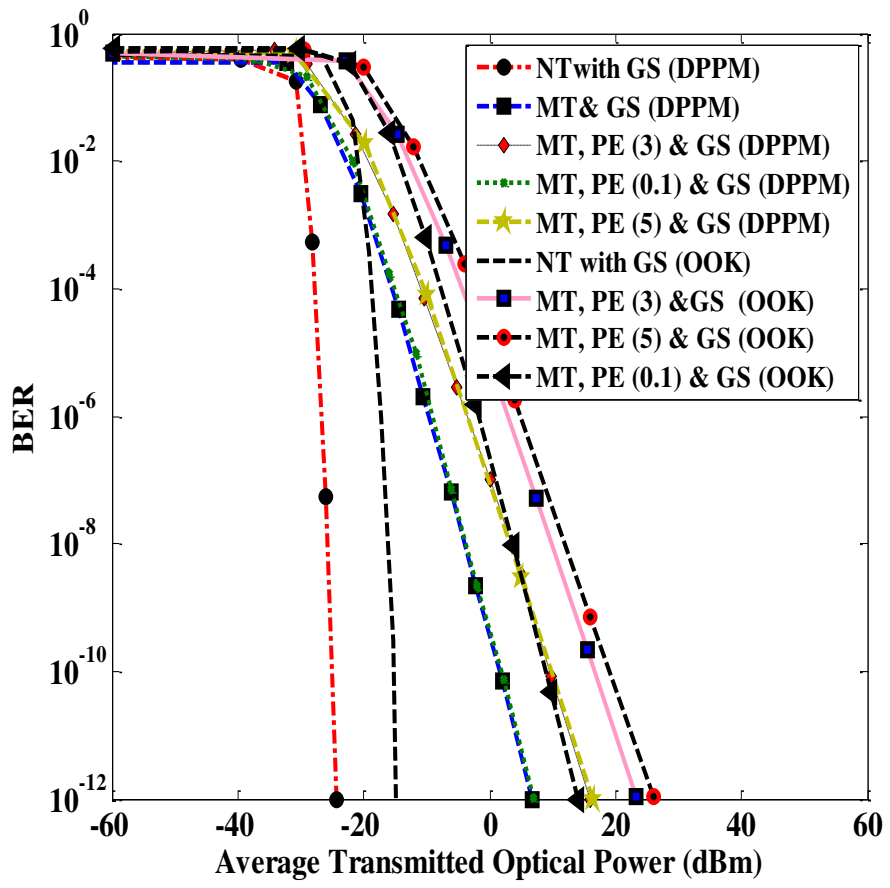

Fig. 3 MCB BER as a function of average transmitted optical power $(\mathrm{dBm})$ for normalized pointing error (PE) standard deviation $\sigma_{P E} / r_{R X}=0.1,3 \& 5, \mathrm{M}=5, \mathrm{G}=30 \mathrm{~dB}$ for no turbulence (NT) with geometric spread (GS), MT only with geometric spread (GS), no pointing error (PE) and combined MT, $\mathrm{PE}$ and GS with $\mathrm{D}_{\mathrm{RX}}=25 \mathrm{~mm}$
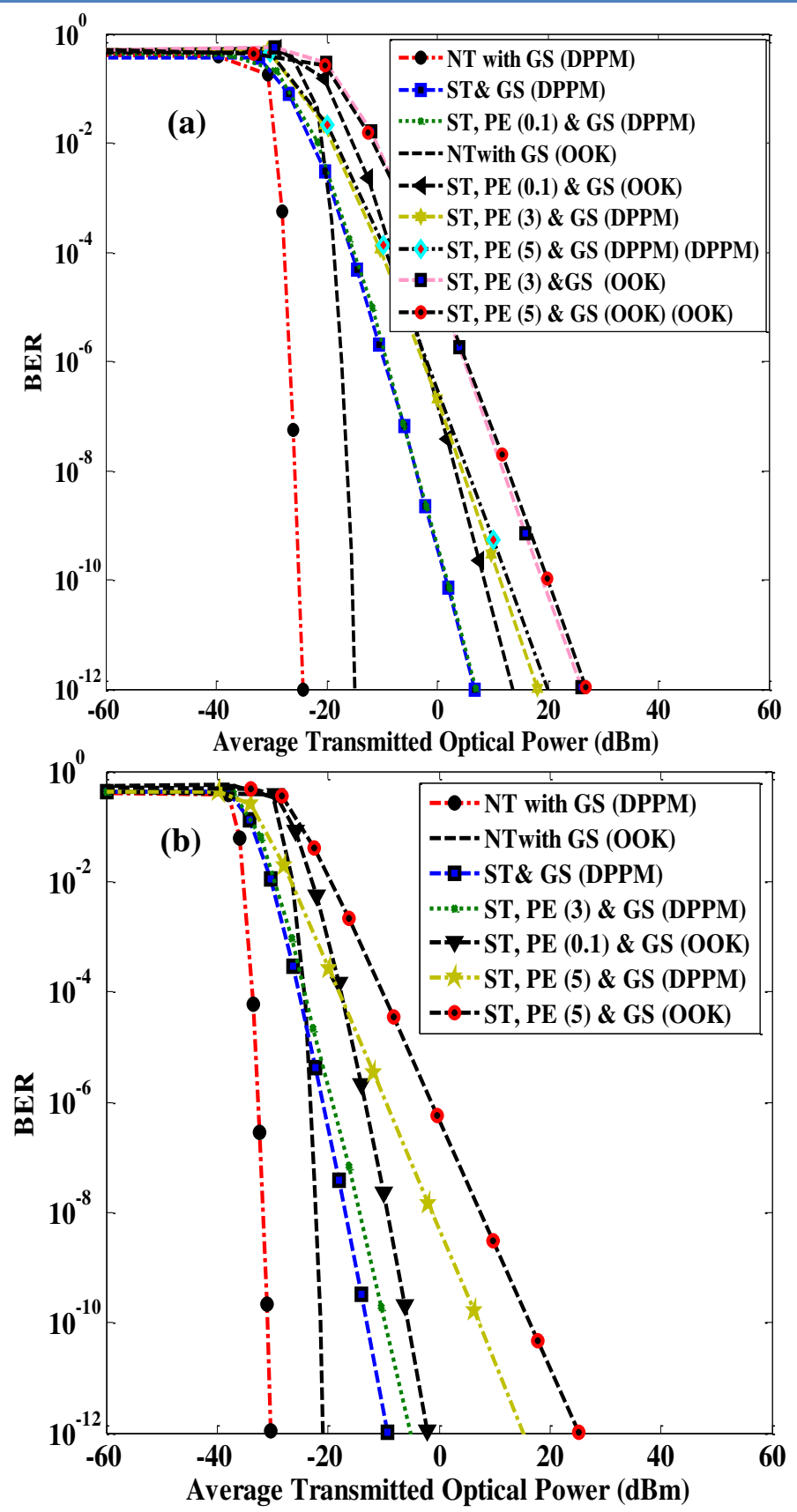

Fig. 4 MCB BER as a function of average transmitted optical power $(\mathrm{dBm})$ for normalized PE standard deviation $\sigma_{\mathrm{PE}} / \mathrm{r}_{\mathrm{RX}}=$ $0.1,3 \& 5, \mathrm{M}=5, \mathrm{G}=30 \mathrm{~dB}$ for NT with GS, ST only with GS, no PE and combined ST, PE and GS with (a) $\mathrm{D}_{\mathrm{RX}}=25 \mathrm{~mm}$ and (b) $\mathrm{D}_{\mathrm{RX}}=50 \mathrm{~mm}$ 
Table 2 Design parameters required for a FSO link

\begin{tabular}{ll}
\hline Design Parameter & Symbol \\
\hline Receiving lens diameter & $\mathrm{D}_{\mathrm{RX}}$ \\
Beam divergence angle & $\varphi$ \\
Optical link length & $l_{\mathrm{fso}}$ \\
Refractive index structure constant & $\mathrm{C}_{\mathrm{n}}^{2}$ \\
Plane wave spatial coherence radius & $\rho_{0}$ \\
Normalized pointing error standard deviation & $\sigma_{\mathrm{PE}} / \mathrm{r}_{\mathrm{RX}}$ \\
\hline
\end{tabular}
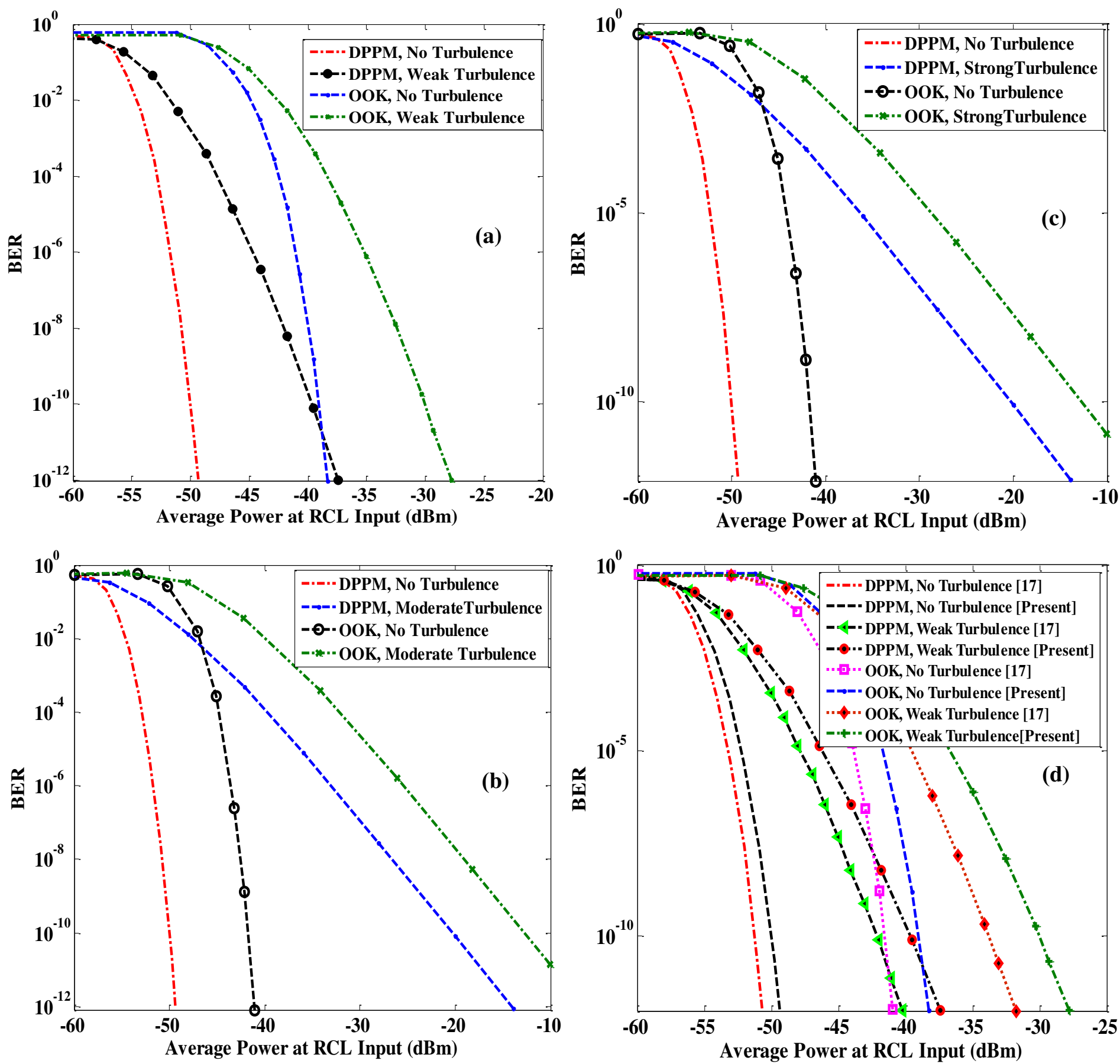

Fig. 5 shows BER vs. average power at receiver collecting lens (RCL) input $(\mathrm{dBm})$ for DPPM and OOK using MCB, while $\mathrm{M}=$ 5, $l_{f s o}=2000 \mathrm{~m}, \mathrm{G}=30 \mathrm{~dB}$, and $\mathrm{D}_{\mathrm{RX}}=25 \mathrm{~mm}$ for NT. (a) WT, (b) MT, (c) ST and (d) comparison for no turbulence and weak turbulence, that presented in [17], [present], all AA 
In Fig. 5 shows BER vs. average power at receiver collecting lens $(\mathrm{RCL})$ input $(\mathrm{dBm})$ for DPPM and OOK using MCB, while $\mathrm{M}=5, l_{\text {fso }}=2000 \mathrm{~m}, \mathrm{G}=30 \mathrm{~dB}$, and $\mathrm{D}_{\mathrm{RX}}=25 \mathrm{~mm}$ for NT and (a) WT (b) MT (c) ST, (d) comparison for no turbulence and weak turbulence, that presented in [17], [Present], all with aperture averaging (AA). A comparison is made between DPPM at $\mathrm{M}=5$ and an equivalent optically preamplified OOK-NRZ FSO system using $l_{\text {fso }}=1500 \mathrm{~m}, D_{\mathrm{RX}}=20 \mathrm{~mm}$ and $\mathrm{MCB}$ method for both systems. At target BER (using MCB), DPPM offers about $10-11 \mathrm{~dB}$ sensitivity improvements over the OOKNRZ-FSO system in the absence of turbulence. When impaired by turbulence, the sensitivity improvement of DPPM over OOK-NRZ is reduced, respectively, to about $10 \mathrm{~dB}$ (WT), $8 \mathrm{~dB}(\mathrm{MT})$ and $8 \mathrm{~dB}$, (ST) [Present]. An improvement of about $7-9 \mathrm{~dB}$ (depending on the turbulence level) can be potentially achieved using the DPPM scheme over an equivalent on off keyed non return-to-zero based FSO system that presented in [17] .When impaired by turbulence, the sensitivity improvement of DPPM over OOK-NRZ is reduced, respectively, to about $7 \mathrm{~dB}$ (WT), $8 \mathrm{~dB}(\mathrm{MT})$ and $8 \mathrm{~dB}$, (ST) [17]. Fig. 6 shows a comparison of the GA, CB and MCB performance at high gain (a) $\mathrm{G}=27 \mathrm{~dB}$ [42] and $\mathrm{G}=30 \mathrm{~dB}$ [Present] with a single crosstalk source for $\mathrm{M}=$ 2 and (b) $\mathrm{G}=8 \mathrm{~dB}$.

\section{Conclusions}

This paper has outlined the effect of combined turbulence and pointing error for an optically preamplified DPPM FSO communication system. Bit-error rate modelling for optically pre-amplified OOK FSO system operating over atmospheric turbulence is investigated using MGF-based techniques such as CB and MCB. The DPPM scheme represent a promising means of further enhancing the FSO power efficiency with significant improvements over OOK NRZ maintained over a range of conditions. The results show a considerable improvement in receiver sensitivity over OOK NRZ using the DPPM technique. The use of aperture-averaging as turbulence mitigating approach is demonstrated with the results showing significant improvements, especially in the MT and ST regimes.

\section{References}

[1] Andrews, L.C., Phillips, R.L.: 'Laser beam propagation through random media' (SPIE Press, Bellingham, Washington, 2nd edn, 2005

[2] Caplan, D.O.: 'Laser communication transmitter and receiver design', J. Opt. Fibre Commun. Rep., 4, pp. 225-362,2007

[3] Majumdar, A.K.: 'Free-space laser communication performance in the atmospheric channel', J. Opt. Fiber Commun. Res., 2, pp. 345-396, 2005

[4] Mukherjee, B.: 'WDM optical communication networks: progress and challenges', IEEE J. Sel. Areas Commun., 2000, 18, (10), pp. 1810-1824, 2000
[5] Ciaramella, E., Arimoto, Y., Contestabile, G., et al.: '1.28 Terabit/s $(32 \times 40 \mathrm{Gbit} / \mathrm{s})$ wdm transmission system for free space optical communications', IEEE J. Sel. Areas Commun., 27, (9), pp. 1639-1645, 2009

[6] Forin, D.M., Beleffi, G.M.T., Curti, F., et al.: 'On field test of a wavelength division multiplexing free space optics transmission at very high bit rates'. Ninth Int. Conf. Telecommunication, pp. 77-80, 2007

[7] Ansari, N., Zhang, J.: 'Media access control and resource allocation for next generation passive optical networks' (Springer, 2013)

[8] Zuo, T.J., Phillips, A.J.: 'Performance of burst-mode receivers for optical digital pulse position modulation in passive optical network application', IET Optoelectron., 3, (3), pp. 123-130, 2009

[9] Bongtae, K., Byoung-Whi, K.: 'WDM-PON development and deployment as a present optical access solution'. Conf. on Optical Fiber Communications - includes Post Deadline Papers, pp. $1-3,2009$

[10] Nirmalathas, Ke, Lim, W., , Skafidas, A., , C., , E.: ‘4 $\times 12.5 \mathrm{~Gb} / \mathrm{s}$ WDM optical wireless communication system for indoor applications', J. Lightwave Technol., 29, (13), pp. 1988-1996, 2011

[11] Aladeloba, A.O., Woolfson, M.S., Phillips, A.J.: 'WDM FSO network with turbulence-accentuated interchannel crosstalk', J. Opt. Commun. Netw., 5, (6), pp. 641-651, 2013

[12] Gee-Kung, C., Chowdhury, A., Zhensheng, J., et al.: 'Key technologies of WDM-PON for future converged optical broadband access networks [invited]', IEEE/OSA J. Opt. Commun. Netw., 1, (4), pp. C35C50, 2009

[13] Kazovsky, L., Shing-Wa, W., Ayhan, T., Albeyoglu, K.M., Ribeiro, M.R.N., Shastri, A.: 'Hybrid opticalwireless access networks', Proc. IEEE, 100, (5), pp. 1197-1225, 2012

[14] Liaw, S.K., Lai, Y.T., Chang, C.L., Shung, O.: 'AWGbased WDM-PON monitoring system using an optical switch and a WDM filter', Laser Phys., 18, (9), pp. 1052-1055, 2008

[15] Phillips, A.J., Cryan, R.A., Senior, J.M.: 'An optically preamplified intersatellite PPM receiver employing maximum likelihood detection', IEEE Photon. Technol. Lett., 8, (5), pp. 691-693, 1996

[16] Muhammad, S.S., Gappmair, W., Leitgeb, E.: 'PPM channel capacity evaluation for terrestrial FSO links'. Proc. Int. Workshop on Satellite and Space Communicaton, pp. 222-226, 2006

[17] Aladeloba, A.O., Phillips, A.J., Woolfson, M.S.: 'Performance evaluation of optically preamplified digital pulse position modulation turbulent free-space optical communication systems', IET Optoelectron., 6, (1), pp. 66-74, 2012

[18] Aldibbiat, N.M., Ghassemlooy, Z., McLaughlin, R.: 'Indoor optical wireless systems employing dual header 
pulse interval modulation (DH-PIM)', Int. J. Commun. Syst., 18, (3), pp. 285-305, 2005

[19] Ghassemlooy, Z., Popoola, W., Rajbhandari, S.: 'Optical wireless communications - system and channel modelling with MATLAB' (CRC Press, London, 1st edn, 2013)

[20] Farid, A. A., Hranilovic, S.: Outage capacity optimization for free-space optical links with pointing errors, J. Lightwave Technol., vol. 25, no. 7, pp. 17021710, 2007

[21] Sandalidis, H. G., et al.: BER performance of FSO links over strong atmospheric turbulence channels with pointing errors, IEEE Communications Letters, vol. 12, no. 1, pp. 44-46, 2008

[22] Aladeloba, A. O., et al.: Improved bit error rate evaluation for optically pre-amplified free-space optical communication systems in turbulent atmosphere, IET Optoelectronics, vol. 6, pp. 26-33, Feb. 2012

[23] Yamamoto, Y., "Noise and error rate performance of semiconductor laser amplifiers in PCM-IM optical transmission systems," IEEE Journal of Quantum Electronics, vol. 16, no. 10, pp. 1073-1081, Oct. 1980

[24] Personick, S. D., "Applications for quantum amplifiers in simple digital optical communication systems," Bell System Technical Journal, vol. 52, no. 1, pp. 117-133, Jan. 1973

[25] Ribeiro, L. F. B., Da Rocha, J. R. F., and Pinto, J. L., "Performance evaluation of EDFA preamplified receivers taking into account intersymbol interference," Journal of Lightwave Technology, vol. 13, no. 2, pp. 225-232, Feb. 1995

[26] Abtahi, M., Lemieux, P., Mathlouthi, W., Rusch, L.A.: 'Suppression of turbulence-induced scintillation in freespace optical communication systems using saturated optical amplifiers', J. Lightwave Technol., 24, (12), pp. 4966-4973, 2006

[27] Lesson, M. S., "Pulse position modulation for spectrum-sliced transmission," IEEE Photonic Technology Letter, vol. 4, no. 3, pp. 1191-1193, Apr. 2004

[28] Davidson, F. M. and Sun, X. M., "Slot clock recovery in optical PPM communication systems with Avalanche photodiode photodetectors," IEEE Trans. Commun., vol. 37, no. 11, pp. 1164- 1172, Nov. 1989

[29] Sun, X. M. and Davidson, F. M., "Word timing recovery in direct detection optical PPM communication systems with Avalanche photodiodes using a phase lock loop," IEEE Trans. Commun., vol. 38, no. 5, pp. 666-673, May 1990

[30] Karp, S., Gagliardi, R.M., Moran, S.E., Stotts, L.B.: 'Optical channels: fibers clouds water and the atmosphere' (Plenum Press, New York, 1988)

[31] Zhu, X., Kahn, J.M.: 'Free-space optical communication through atmospheric turbulence channels', IEEE Trans. Commun., 50, (8), pp. 12931300, 2002
[32] Al-Habash, M.A., Andrews, L.C., Phillips, R.L.: 'Mathematical model for the irradiance probability density function of a laser beam propagating through turbulent media', Opt. Eng., 40, (8), pp. 1554-1562, 2001

[33] Khalighi, M.A., Schwartz, N., Aitamer, N., Bourennane, S.: 'Fading reduction by aperture averaging and spatial diversity in optical wireless systems', IEEE/OSA J. Opt. Commun. Netw., 1, (6), pp. 580-593, 2009

[34] Vetelino, F.S., Young, C., Andrews, L.: 'Fade statistics and aperture averaging for Gaussian beam waves in moderate-to-strong turbulence', Appl. Opt., 46, (18), pp. 3780-3789, 2007

[35] Yuksel, H., Davis, C.: 'Aperture averaging experiment for optimizing receiver design and analyzing turbulence on free-space optical communication links'. Conf. on Lasers and Electro-Optics (CLEO), Baltimore, MD, USA, pp. 743-745, May 2005

[36] Aladeloba, A. O., Phillips, A. J., and Woolfson, M. S., "DPPM FSO communication systems impaired by turbulence, pointing error and ASE noise," in 14th Int. Conf. on Transparent Optical Networks (ICTON), Coventry, UK, 2012

[37] Sibley, M.J.: 'Optical communications' (Macmillian Press Ltd, London, 2nd edn, 1995.)

[38] Ramaswami, R., Sivarajan, K. N., Sasaki, G. H. Optical Networks: A Practical Perspective. 3rd ed. Boston: Morgan Kaufmann Publishers; 2010

[39] Mizumoto, Maru, K., Uetsuka, T., , H.: 'Demonstration of Flat-Passband Multi/Demultiplexer Using MultiInput Arrayed Waveguide Grating Combined With Cascaded Mach-Zehnder Interferometers'. J. Lightw. Technol., 25, (8), pp.2187-2197, 2007

[40] Hirano, A., Miyamoto, Y., Kuwahara, S.: 'Performances of CSRZ-DPSK and RZDPSK in 43Gbit/s/ch DWDM G.652 single-mode-fiber transmission'. Optical Fiber Commun. Conf., 2003, pp. 454-456, 2003

[41] Yu, C. X., Neilson, D. T.: 'Diffraction-grating-based (de)multiplexer using image plane transformations'. IEEE J. Selected Topics in Quantum Electronics,, 2002, 8, (6), pp. 1194-1201, 2002

[42] Mbah, A.M., Walker, J.G., Phillips, A.J.: 'Performance evaluation of digital pulse position modulation for wavelength division multiplexing FSO systems impaired by interchannel crosstalk', IET Optoelectron., 8, (6), pp. 245-255, 2014

[43] Henry, P. S., Error-rate performance of optical amplifiers, Optical Fiber Communication Conference, Houston, Texas, vol. 5, Feb. 1989

[44] ZhaoZ, Z., Tan, J., Liu, Y., Liu, J..: '200 Gb/s FSO WDM Communication System Empowered by Multiwavelength Directly Modulated TOSA for $5 \mathrm{G}$ Wireless Networks', IEEE Photonics Journal, vol. 10, no. 4 , pp. 1943-0655, Aug. 2018

[45] eprints.nottingham.ac.uk, 2018 
[46] Hien T. T. Pham., Ngoc T. Dang: Performance improvement of spatial modulation-assisted FSO systems over Gamma-Gamma fading channels with geometric spreading, Photon Netw Commun, 34, pp.213-220, 2017 
Figures

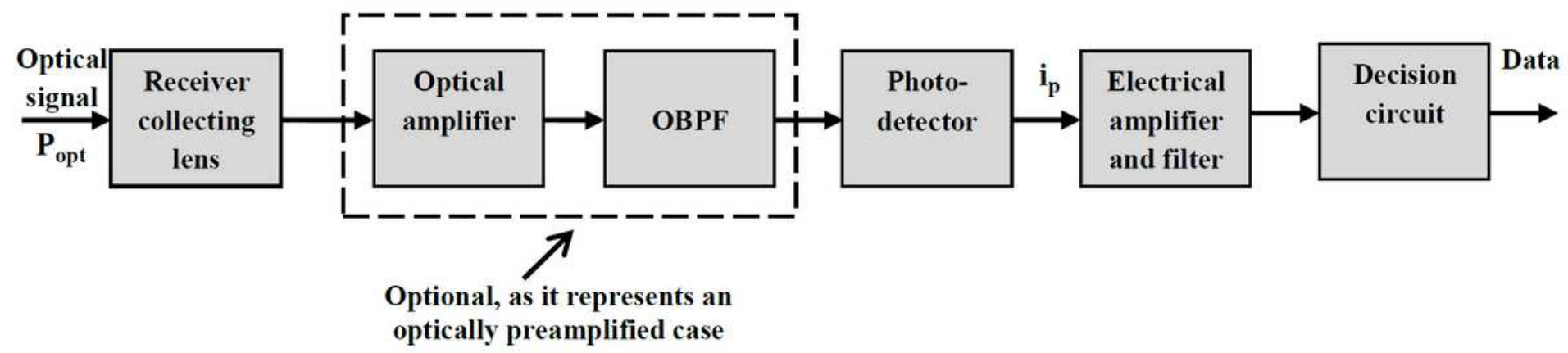

Figure 1

Block diagram of optically FSO receiver 

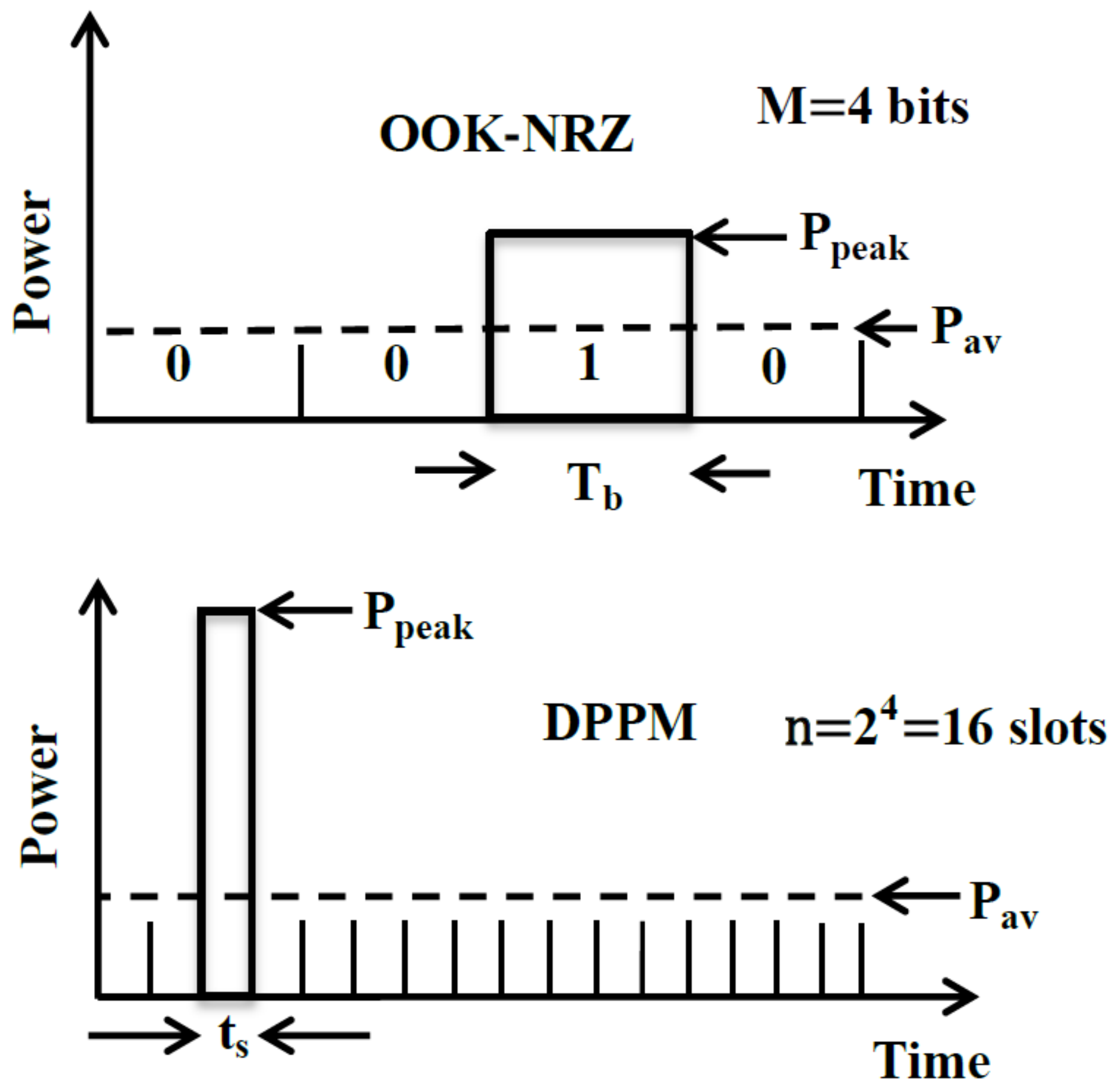

Figure 2

Illustration of OOK-NRZ and DPPM frame for $M=4$ ( $n=2^{\wedge} 4=16$ slots) 


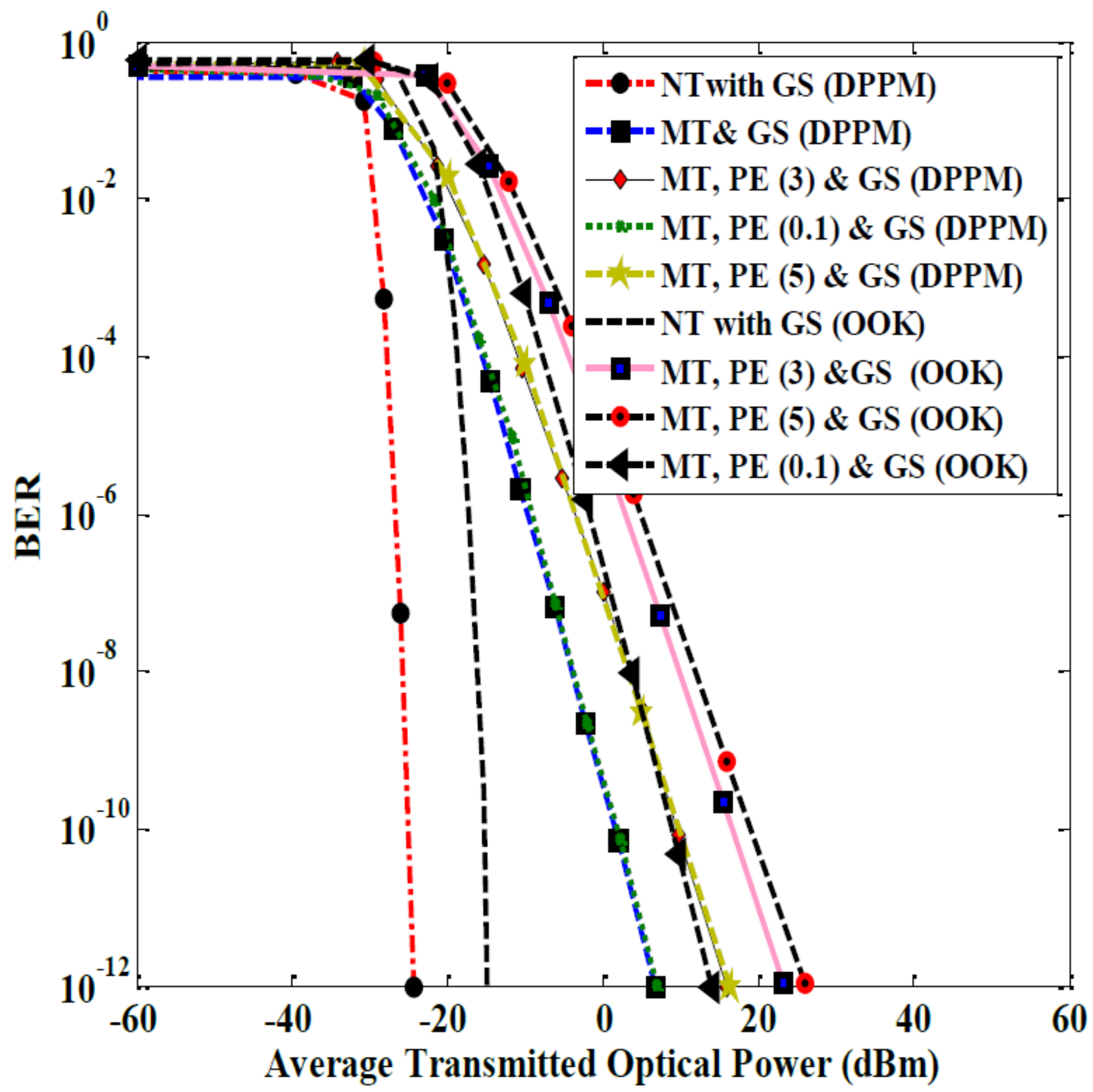

Figure 3

MCB BER as a function of average transmitted optical power $(\mathrm{dBm})$ for normalized pointing error (PE) standard deviation $\sigma P E / r R X=0.1,3 \& 5, M=5, G=30 \mathrm{~dB}$ for no turbulence (NT) with geometric spread (GS), MT only with geometric spread (GS), no pointing error (PE) and combined MT, PE and GS with DRX $=25 \mathrm{~mm}$ 

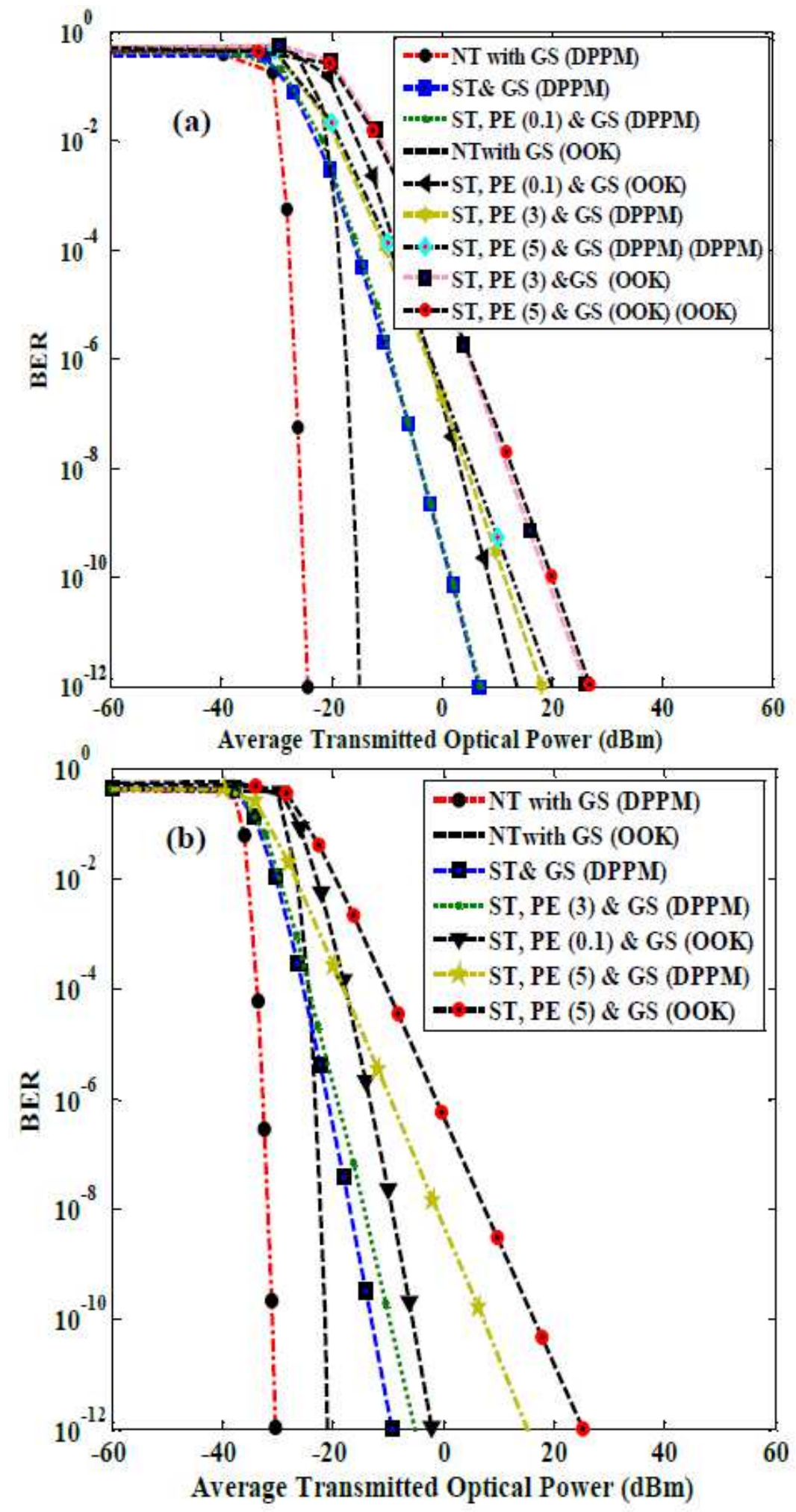

Figure 4

MCB BER as a function of average transmitted optical power $(\mathrm{dBm})$ for normalized PE standard deviation $\sigma P E / r R X=0.1,3 \& 5, M=5, G=30 \mathrm{~dB}$ for NT with GS, ST only with GS, no PE and combined ST, PE and GS with (a) DRX $=25 \mathrm{~mm}$ and (b) $\mathrm{DRX}=50 \mathrm{~mm}$ 

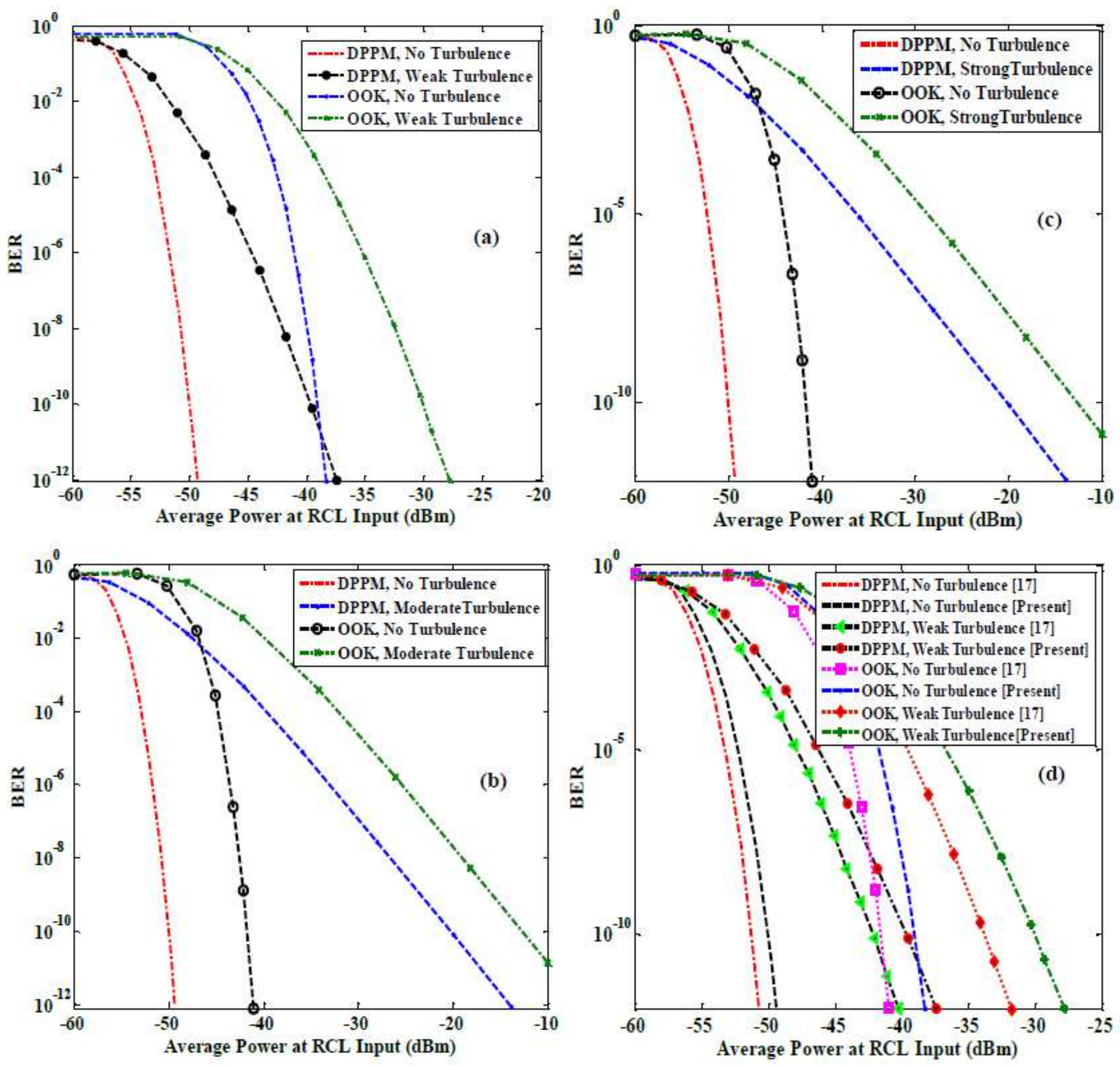

Figure 5

shows BER vs. average power at receiver collecting lens (RCL) input (dBm) for DPPM and OOK using $M C B$, while $M=5$, Ifso $=2000 \mathrm{~m}, \mathrm{G}=30 \mathrm{~dB}$, and DRX= $25 \mathrm{~mm}$ for NT. (a) WT, (b) MT, (c) ST and (d) comparison for no turbulence and weak turbulence, that presented in [17], [present], all AA 